\title{
A REVIEW: BOTANICAL PESTICIDE AN ECOFRIENDLY APPROACH
}

\section{R. NASEEMA ${ }^{1}$, K. GILBERT ROSS REX ${ }^{2 *}$, R.S. DAVID PAUL RAJ ${ }^{3} \&$ N. PRABHU ${ }^{4}$}

${ }^{1,2 *, 4}$ Department of Biotechnology, Vivekanandha College of Engineering for Women, Namakkal, Tamil Nadu, India

${ }^{3}$ Department of Biotechnology, Karunya Institute of Technology and Sciences, Coimbatore, Tamil Nadu, India

ABSTRACT
Current scenario depicts the loss of yield in agriculture production due to effective activity of harmful root knot
nematodes. Among all the species of root knot nematodes, Meloidogyne incognita has examined as the most destructive
nematode all over the world. Many complications have been highlighted by the usage of artificial pesticides due its
negative impact on soil fertility and biological system. Alternative to artificial pesticides have been analysed in different
plant species. Many plant species have nematocidal activity against RKNs. But still the best alternative is in search.
KEYWORDS: Artificialpesticides, Meloidogyne Incognita, Nematocidal Activity, RKN-Root Knot Nematodes

Received: May 10, 2020; Accepted: Jun 30, 2020; Published: Jun 30, 2020; Paper Id.: IJMPERDJUN2020238

\section{INTRODUCTION}

Synthetic pesticides have been shown to be very effective in eliminating plant pests and diseases, but they also pose a harm to the environment and human health (Sill, 1982). Occurrence of crop nematode problems has been increasing recently by modifying the cropping procedure in order to meet the increase in demand for food consumption worldwide (Yassin et al. 1992). Harm-full effect of the plant nematodes, specifically by root nematodes, leads to difficulty in the manufacture of a satisfactory nutrient supply (Carter and Sasser, 1982). Minute or no harm -full effect was noticed on non-targeted organisms by the selected natural products. Bhatti et al. (1994) proved that $30 \%$ of yield losses under field conditions is by M. incognita. This causes severe trouble for various annual and perennial crops. The favourable condition for the imitation and nourishing events of plant parasitic nematodes all over the year is achieved in a large tropical country named as Sudan (Elbadri et al. 2008). On every side of tropical places in the world, root knot nematodes (Meloidogyne species) have been known as the most copious and devastating nematode. These species are mostly parasitizing sum of plant species belonging to Families Cucurbitaceae and Solanaceae (Taba et al. 2008). These leads to yellowing of leaves and reductions in their growth and yield. Therefore, the typical signs are the formation of galls on roots due to the development of giant cells (Fig.1). All over the world crop yield losses have been exceeded by US $\$ 125$ billion (Chitwood, 2003). Nematicidal activities have been found in plant products of 57 different families (Sukul, 1992), (Latif et al. 2014). Meloidogyne spp., caused world-wide financial threat by the harmful effect in both humid and subtropical crop production regions (Sikora et al. 2005). About 200 plant species together with herbaceous and woody-plants of monocotyledon and dicotyledons are affected by this root parasitic nematode (Hussey, 1985). Almost $90 \%$ of damage is caused by M. incognita (Krechel et al. 2002). The most significant and agriculture efficiency and quality diminishing pathogens are the root-knot nematodes (Meloidogyne spp.) (Tylenchina: Meloidogynidae) (RKNs) amongst all plant-parasitic nematodes (Irshad et al. 2006), (Yen et al. 2004). M.incognita is the utmost pathogenic nematode, including Turkey, M. incognita, M. arenaria Chitwood, M. javanica (Treub) Chitwood and M. hapla Chitwood 
commonly found in RKN species (Kepenekci et al. 2016).

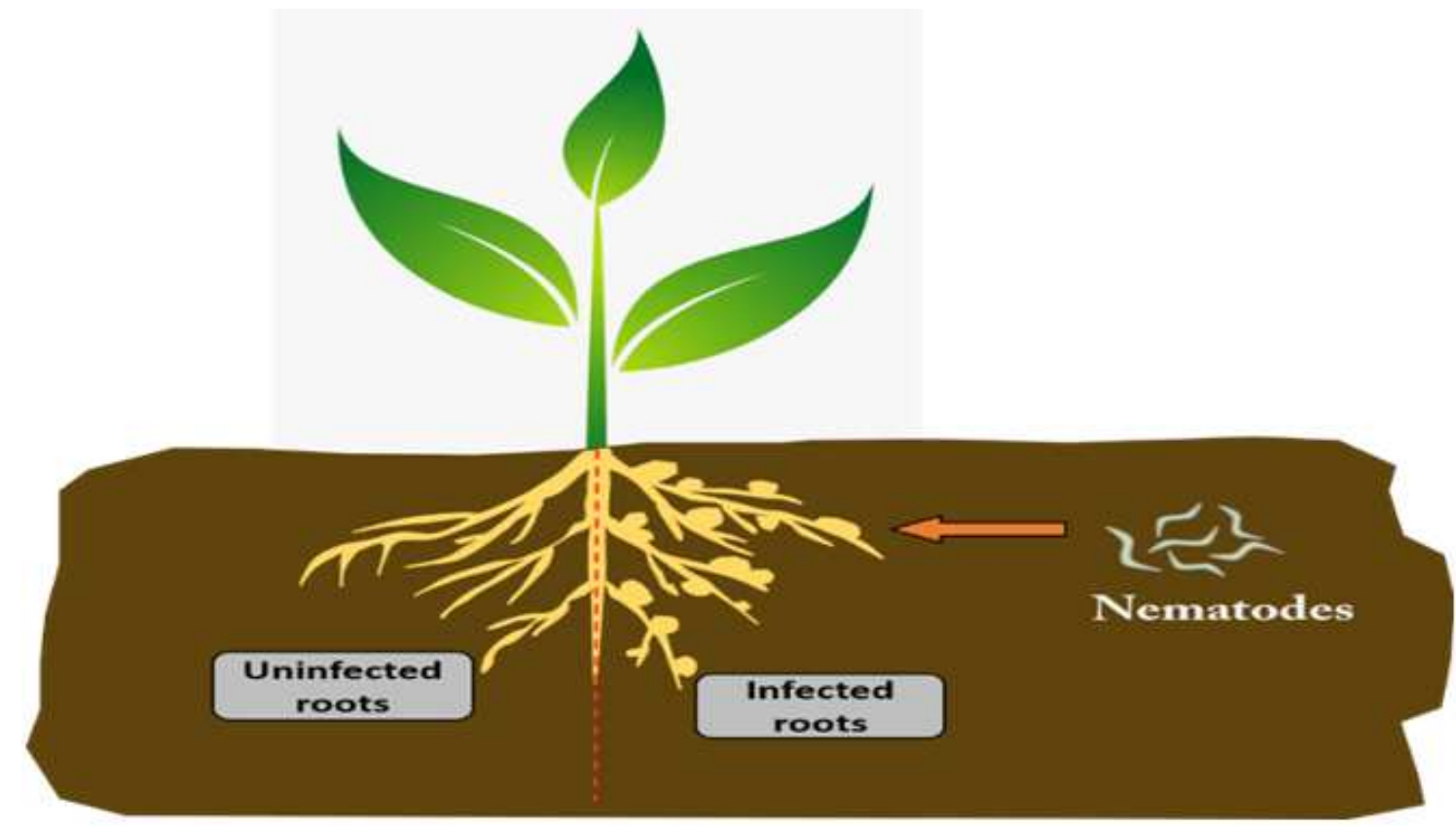

Figure 1: Plant Showing Uninfected and Infected Root Phenotypes.

\section{SIGNIFICANCES}

Great contribution to nitrogen and phosphorus cycles and to soil fertility by the fee living nematodes. Plant-parasitic nematodes for example

The bacterial, omnivorous, hyphal-feeding and predacious nematodes co-inhabit the loam (Ajitomi et al. 2017). Probably, these are present in different types of environment and free-living nematodes exist in the soil, fresh water, marine sands and muds. Nematodes have a significant niche in agro-ecosystem triggering reduction in plant productivity and growth (Azhagumurugan et al. 2013). In general, the chief allelopathic effect in flowering stage is seen in plants, so at that time nematotoxic compounds are produced in highest quantity (Ajitomi et al. 2017). Additionally, root knot nematodes in the presence of other biotic and abiotic stresses generate more complex contagium.

These aspects along with a high generative rate of the nematodes make it hard to achieve root knot parasitism (Latif et al. 2014). Impairment of microorganisms such as fungi, earthworms and bacteria and soil biomass is executed by pesticides. The Soil nutrient element cycle consists of soil organic matter such as microbial biomass. Mutilation of local metabolism and impression on non- target organisms are achieved by the usage of pesticides which are essential for soil fertility. It has been expected that the practice of pesticides in 2050 will be 2.7 times greater than in 2000 . In the period of 2-20 years, a lot of new resistant cases have been stated. Even after the start of novel modules of insecticides like cyclodienes, formamidine, organophosphates, carbamates and pyrethroids. The dosage of pesticides was increased by times the amount added before due to the ineffectiveness in the pest resistance. Although the use of fungicides is to protect crops from diseases and insecticides are to kill pests of plants. A study exhibits that a type of commonly used (96\%) pesticide by the farmers is known as Arjuna. It comprises an ingredient from the payroll group known as chlorfenapyr active compound. WHO declared it as the temperately hazardous insecticide (Joko et al. 2017).Mostly in the tropics and subtropics of many countries, a stern production loss is seen in a wide variety of crops (Sasser \& Freckman, 1987; Luc et 
al. 2005). Present supervision of nematodes is fixated on, cultural practices or chemical nematicides, crop rotation, plant resistance (Chitwood et al. 2002), (Kepenekci et al. 2016). The farmers are using huge quantity of pesticides once in every three or four days. About three insecticides and fungicides types are slightly combined around 30-40ml for each type. The land degradation potential was seen by the extreme usage of pesticides (Taniwiryono et al. 2009).

\section{ALTERNATIVES}

Artificial nematicides are one of the chief sources of control in strenuously full -fledged crops (Zuckerman and Esnard, 1994). A worthwhile key solution to the synthetic pesticides that creates environmental problems is being found out by the researchers (Park et al. 2005). An active protocol of pesticide discovery is seeing the possibility of plant secondary harvests being tangled in plant-pest relations, the tactic of casually isolating, recognizing, and bio-assaying these composites (Duke, 1990). Plenty of plants are found to be extremely impervious to plant pathogens, insect pests and plant parasitic nematode. For example, chrysanthemums (Chrysanthemum spp.), rattlebox (Crotalaria spectabilis), cinnamon (Cinnamomum verum), marigolds (Tagets spp.),garlic (Allium sativum) and neem

(Azardiracta indica) (Satti and Naser, 2006; Elbadri et al. 2008; Kong et al. 2007; Park et al. 2005; Duke, 1990). Many chemicals were effectually used to decrease loss due to nematode parasitism (Abad et al. 2008). Many beneficial things have been found by the usage of different plant products against nematode parasitism, when related to methods like informal accessibility and applicability, cost effective, growing soil fertility and no harmful effects on the atmosphere (Kumar et al. 2005). Consumption of pesticides from plant origin, called as botanical pesticides. As they are already malformed by oxygen, microorganisms and light into less toxic products they are measured to be non-persistent beneath field environment. Thus, no deposits are predicted on the products or in the environment (Taniwiryono et al. 2009). Due to these limitations, studies show that natural compounds with nematicidal activity such as a plant extract, root exudates, plant volatiles etc. Sliced pine-apple (Annanascomosus (L.) Merr. (Poales: Bromeliaceae)) Leaves were used as an organic amendment against Meloidogyne spp.,initiate to study the nematicidal effect by Linford et al. (1938). It was assumed that nematicidal compounds were present in several plant species, demonstrating 57 families together with Rutaceae, Asteraceae, Myrtaceae, Lauraceae, Lamiaceae (Andres et al. 2012; Sukul, 1992). Mediterranean coast is recently becoming the important site for research on the practice of plant extracts as a substitute to synthetic pesticides for RKNs resistance. (Bosselut et al. 2011; Andres et al. 2012; Kepenekci et al. 2016). For the production of innovative pesticidal compounds, plants produce chemicals that are the novel source of advance chemistry. Nematicidal phytochemicals are commonly safe for human as well as the environment (Chitwood et al. 2002). Nematicidal activity has been identified in plant essential oils, mainly monoterpenes. They were extremely active in the nematode destruction (Oka et al. 2000; Oka et al. 2006). There is still continuous usage of synthetic pesticides or soil fumigants instead of other methods like e.g. improving cultural practices, using natural enemies and growing resistant cultivators. Developing new alternatives for controlling nematodes is necessary due to the highlighted complications. One such promising strategy is the use of plant compounds for demolishing nematodes, as these are cheap, eco-friendly, easily available and have the strength to recover the cause (Liu et al. 2014).

\section{CONCLUSIONS}

The review exhibits the disadvantage of chemical pesticides on the environment. Still, there is a need for research to identify the best alternative for chemical pesticide such as botanical pesticide. 


\section{REFERENCES}

1. Abad, Pierre, Jérôme Gouzy, Jean-Marc Aury, Philippe Castagnone-Sereno, Etienne GJ Danchin, Emeline Deleury, Laetitia Perfus-Barbeoch et al. (2008), “Genome sequence of the metazoan plant-parasitic nematode Meloidogyne incognita”,Nature biotechnology 26: 909-915.

2. Ajitomi, Atsushi, Satoshi Taba, Yoshino Ajitomi, Misa Kinjo, and Ken-taro Sekine. (2017), "Efficacy of a simple formulation composed of nematode-trapping fungi and Bidenspilosa var. radiata Scherff aqueous extracts (BPE) for controlling the Southern root-knot nematode”, Microbes and environments, ME17110.

3. Andres, Maria Fe, Azucena González-Coloma, Jesus Sanz, Jesus Burillo, and Paula Sainz. (2012), "Nematicidal activity of essential oils: a review", Phytochemistry Reviews 11, no. 4, 371-390.

4. Azhagumurugan, C., and M. K. Rajan. (2013), "Nematicidal Activities of Leaf Extract of Magilam, Mimusopselengi against the Egg Hatchability and Larval Mortality of Root Knot Nematode Meloidogyne incognita”,European Journal of Applied Sciences 5: 80-83.

5. Bhatti, D. S., and R. K. Jain. (1994), “Crop cultivars resistant to nematodes, Nematode Pest Management in Crops”,(eds.) DD Bhatti and RK Walia, CBS Publishers and Distributors, New Delhi 215-227.

6. Bosselut, Nathalie, Cyril Van Ghelder, Michel Claverie, Roger Voisin, Jean-Paul Onesto, Marie-Noëlle Rosso, and Daniel Esmenjaud (2011), "Agrobacterium rhizogenes-mediated transformation of Prunus as an alternative for gene functional analysis in hairy-roots and composite plants." Plant cell reports 30, no. 7: 1313.

7. Carter, C. C., and Joseph Neal Sasser. (1982), "Research on integrated crop protection systems with emphasis on the rootknot nematodes (Meloidogyne spp.) affecting economic food crops in developing nations”. No. 632.6513 C323. North Carolina State University, Raleigh, NC (EUA). International Meloidogyne Project.

8. Chitwood, David J. (2002), "Phytochemical based strategies for nematode control”,Annual review of phytopathology 40, no. 1,221-249.

9. Chitwood, David J. (2003), "Research on plant parasitic nematode biology conducted by the United States Department of Agriculture-Agricultural Research Service." Pest Management Science: formerly Pesticide Science 59, no. 67: 748-753.

10. Duke, S. O. (1990), "Advances in new crops." Natural pesticides from plants : 511-517.

11. Elbadri, Gamal Abdalla, Dong Woon Lee, Jung Chan Park, Hwang Bin Yu, and Ho Yul Choo. (2008), "Evaluation of various plant extracts for their nematicidal efficacies against juveniles of Meloidogyne incognita”,Journal of Asia-Pacific Entomology 11: 99-102.

12. Hussey, R. S. (1985), "Staining nematodes in plant tissue”, Plant Nematology Laboratory Manual. Amherst, MA: The University of Massachusetts Agriculture Experiment Station, 197-199.

13. Irshad, Lubna, S. H. A. H. N. A. Z. Dawar, M. Javed Zaki, and A. Ghaffar.(2006), "Effect of nursery fertilizers on plant growth and in the control of Meloidogyne javanica root knot nematode on mung bean and okra plants",Pakistan Journal of Botany 38, no. 4, 1301.

14. Joko, Tri, SutrisnoAnggoro, Henna RyaSunoko, and Savitri Rachmawati.(2017), "Pesticides usage in the soil quality degradation potential in wanasari subdistrict, Brebes, Indonesia”,Applied and Environmental Soil Science 2017.

15. Kong, Jeong-Ok, Sang-Myung Lee, Yil-Seong Moon, Sang-Gil Lee, and Young-Joon Ahn.(2007), "Nematicidal activity of cassia and cinnamon oil compounds and related compounds toward Bursaphelenchusxylophilus (Nematoda: Parasitaphelenchidae)." Journal of nematology 39, no. 1:31. 
16. Kepenekçi, I.(2012), “Nematology: Plant Parasitic and Entomopathogen Nematodes”. Ankara, Turkey: Department of Training.

17. Kepenekci, Ilker, DolunayErdoğuş, and PervinErdoğan.(2016) "Effects of some plant extracts on root-knot nematodes in vitro and in vivo conditions." Türkiye Entomoloji Dergisi 40, no. 1 .

18. Krechel, Annette, AnnekathrinFaupel, Johannes Hallmann, Andreas Ulrich, and Gabriele Berg. (2002), "Potato-associated bacteria and their antagonistic potential towards plant-pathogenic fungi and the plant-parasitic nematode Meloidogyne incognita (Kofoid\& White) Chitwood”, Canadian journal of microbiology 48, no. 9 ,772-786.

19. Kumar, Tarun, Sun-Chul Kang, and Dinesh Kumar Maheshwari. (2005), "Nematicidal activity of some fluorescent pseudomonads on cyst forming nematode, Heteroderacajani and growth of Sesamum indicum var”. RT1,Journal of Applied Biological Chemistry 48, no. 4, 161-166.

20. Latif, Rizwana, Muhammad Wseem Abbasi, and M. JavedZaki. (2014), "Nematicidal activity of bark of some tree species against root knot nematode Meloidogyne javanica (Treub) Chitwood”,FUUAST Journal of Biology 4: 247-251.

21. Linford, M. B., Francis Yap, and Juliette M. Oliveira. (1938), "Reduction of soil populations of the root-knot nematode during decomposition of organic matter", Soil Science 45, no. 2, 127-142.

22. Liu, Xin Chao, L. G. Zhou, and Zhi Long Liu. (2014), "Evaluation of nematicidal activity of ethanol extracts of Euphorbiaceae plants and constituents from Euphorbia fischeriana to Meloidogyne incognita (Kofoid and White) Chitwood". J. Entomol. Zool. Stud 2: 311-317.

23. Luc, Michel, Richard A. Sikora, and John Bridge, (2005) eds., "Plant parasitic nematodes in subtropical and tropical agriculture”. Cabi.

24. Oka, Yuji, Bat-Hen Ben-Daniel, and Yigal Cohen. (2006), "Control of Meloidogyne javanica by formulations of Inulaviscosa leaf extracts",Journal of nematology 38: 46.

25. Oka, Yuji, SengulNacar, Eli Putievsky, Uzi Ravid, Zohara Yaniv, and Yitzhak Spiegel. (2000), "Nematicidal activity of essential oils and their components against the root-knot nematode",Phytopathology 90, no. 7 710-715.

26. Park, Il-Kwon, Kyung-Hee Kim, Kwang-Sik Choi, Chul-Su Kim, In-Ho Choi, Ju-Yong Park, and Sang-Chul Shin. (2005), "Nematicidal activity of plant essential oils and components from garlic (Allium sativum) and cinnamon (Cinnamomumverum) oils against the pine wood nematode (Bursaphelenchusxylophilus)”, Nematology 7, no. 5 ,767-774.

27. Sasser, J. N. (1987), “A world perspective on nematology: the role of the society”, Vistas on Nematology, 7-14.

28. Satti, A.A., Naser, O.E. (2006), "Effect of neem (Azadirachtaindica A. Juss) seed powder and aqueous extracts on the control of some major foliage insect pests of eggplant". Albuhuth 10, 1-16.

29. Sill, W.H.J. (1982), “Plant Protection an Integrated Interdisciplinary Approach”,The Iowa State University press, Ames, Iowa. 291 pp.

30. Sikora, Richard A., and Emilio Fernandez.(2005), "Nematode parasites of vegetables." Plant parasitic nematodes in subtropical and tropical agriculture 2: 319-392.

31. Sukul, N. C. (1992), "Plants antagonistic to plant-parasitic nematodes", Indian Review of Life Sciences 12,23-52.

32. Taba, Satoshi, Juri Sawada, and Zen-ichiMoromizato. (2008), "Nematicidal activity of Okinawa Island plants on the root-knot nematode Meloidogyne incognita (Kofoid and White) Chitwood", Plant and soil 303: 207-216. 
33. Taniwiryono, D., Hv Berg, J. A. G. Riksen, I. M. C. M. Rietjens, S. R. Djiwantia, J. E. Kammenga, and A. J. Murk. (2009), "Nematicidal activity of plant extracts against the root-knot nematode, Meloidogyne incognita”, The open natural products journal 2, no. 1 .

34. Yassin, A. M. (1992), "Sudan. Plant nematode problems and their control in the Near East Region (FAO plant production and protection paper-144)". Eds. by MA Maqbool and B. Kerry, Proceedings of the expert consultation on plant nematode problems and their control in the Near East Region, Karachi, Pakistan, 22-26.

35. Yen, J H., H. Y. Wu, S. F. Lai, D. Y. Chen, and T. T. Tsay. (2004), "Study of a low-temperature and low-pressure fumigation technique for the quarantine procedure of plant parasitic nematodes”, Plant Pathology Bulletin 13, no. 1, 85-90.

36. Zuckerman, Bert M., and Joseph Esnard. (1994), "Biological control of plant nematodes-current status and hypotheses", Nematological Research, Japanese Journal of Nematology 24, no. 1, 1-13.

37. Singh, Rajendra. "Evaluation of nematicidal potency of botanical biopesticides in combination with triazophos against root knot nematode, Meloidogyne incognita infestation on chickpea, Cicer arietinum L." International Journal of Applied and Natural Sciences (IJANS) 4.3 (2015): 75-82.

38. Tapre, Poonam., and H. R. Patel. "Effect of bidi tobacco dust on root-knot nematode (Meloidogyne incognita) attacking okra." International Journal of Agricultural Science and Research (IJASR). 5.2 (2015): 55-58.

39. Hasan, Hussein Hazim, Sobita. Simon, and Abhilasha A. Lal. "Effect of selected botanical extracts against Meloidogyne incognita (Kofoid and White) Chitwood on potato (Solanum tuberosum L.)." International Journal of Agricultural Science and Research (IJASR) 4.3 (2014): 101-108.

40. Munshid, Hayder, Sobita Simon, and A. A. Lal. "Antagonistic potential of Bacillus subtilis and Pseudomonas fluorescens on Meloidogyne incognita of green onion (Allium fistulosum)." International Journal of Botany and Research (IJBR) 3.5 (2013): $15-22$

41. Singh, Rajendra, and Monika Singh. "Medicinal Plant Extracts Against Second Stage Juvenile (J2) of Root Knot Nematode, Meloidogyne Incognita." International Journal of Agricultural Science and Research (IJASR) 6.5 (2016):333-338 